Revue de l'Institut des langues et cultures

d'Europe, Amérique, Afrique, Asie et Australie

39 | 2020

Les humanités numériques dans une perspective internationale : opportunités, défis, outils et méthodes

\title{
Digital Spatial Practices and Linguistic Landscaping in Beirut
}

Pratiques spatiales numériques et aménagement du paysage linguistique à

Beyrouth

\section{David Joseph Wrisley}

\section{CpenEdition}

\section{Journals}

\section{Electronic version}

URL: http://journals.openedition.org/ilcea/9198

DOI: 10.4000/ilcea.9198

ISSN: 2101-0609

\section{Publisher}

UGA Éditions/Université Grenoble Alpes

\section{Printed version}

ISBN: 978-2-37747-174-4

ISSN: 1639-6073

\section{Electronic reference}

David Joseph Wrisley, « Digital Spatial Practices and Linguistic Landscaping in Beirut », ILCEA [Online], 39 | 2020, Online since 03 March 2020, connection on 09 October 2020. URL : http:// journals.openedition.org/ilcea/9198; DOl : https://doi.org/10.4000/ilcea.9198

This text was automatically generated on 9 October 2020 .

(C) ILCEA 


\title{
Digital Spatial Practices and Linguistic Landscaping in Beirut
}

\author{
Pratiques spatiales numériques et aménagement du paysage linguistique à \\ Beyrouth
}

David Joseph Wrisley

\section{Introduction}

1 The language situation of Lebanon has long been a subject of interest to researchers of the Arabic-speaking cultures of the Middle East. In a country known for its multilingual educational system and the transnational mobility of its large diaspora, the spoken vernacular of Lebanon is characterized by a distinctive code-switching. Conversations in the Lebanese capital move between Arabic, French, English, and sometimes Armenian, and when the diaspora visits, more languages can be heard in the cityscape: Spanish, Brazilian Portuguese, German, Danish. Code-switching is not limited to the conversations one can hear, however, it is also reflected in written language found in the physical environment. Any visitor to Beirut is immediately struck by the city's complex "linguistic landscape," (LL) a notion from sociolinguistics dealing with the "visibility and salience of languages on public and commercial signs in a given territory or region" (Landry \& Bourhis, 1997: 23). This article turns to the LL of Beirut, describing some of its complexities and reporting how digital humanities (DH) methods were employed to collect data and analyze linguistic patterns in the cityscape. Finally, the article discusses some higher level conclusions from the study and comments on digital humanities research carried out in non-Western, infrastructurally challenged locations.

2 Beirut is the capital city of Lebanon, a small, multi-sectarian Middle Eastern country located on the eastern coast of the Mediterranean, with about six million inhabitants, eighteen recognized religious communities and a diaspora somewhere between two to four times the size of its national population. After World War One the creation of the French Mandate began to shape the area we now know as the modern Lebanese 
Republic out of what had been the Ottoman administrative unit of Mount Lebanon. With the declaration of the Republic in 1926, its constitutional text adopted French as an official language alongside Arabic, an official status that would be revoked some two decades later at the moment of Independence in 1943 (Traboulsi: 2012, 90 and 108). In spite of the brevity of the official status of French, its influence on Lebanon ever since has been undeniable. English also increased in importance throughout the twentieth century, as in many other places in the world, asserting itself in particular in the realm of national language policy and education, but without ever being declared an official language (Ghaith \& Shaaban, 1999). Debates about national and communitarian identity and Lebanon's complex multilingualism have continued throughout the last century, and unsurprisingly, they emerge still today in a variety of contexts: education, language policy and cultural identity.

If religion and its relations to communitarianism and human geography are hotly debated topics in Lebanon, language use is definitely a close runner up. Language is linked to the cultural identity and diversity of this small state and to the interconnectedness of its many communities. The government-established curriculum dating from the post-civil war period of the 1990s requires instruction in three languages: Arabic, French and English. These languages are described as one official native language and two foreign languages, phased in during elementary school, the first at grade 1 and the second at grade 7. The language of instruction for all subjects is not Arabic, however, and the dominant foreign language in which students study varies from school to school. There is, however, a significant public/private school divide, and in most private education, foreign languages are the main medium of instruction for some topics such as science and mathematics all the way through university. It goes without saying that language use and instruction are intricately intertwined. One must add to that complexity that local opinions about language generally place English or French as more useful than Arabic, since they are perceived to provide important career and business opportunities (Esseili, 2014).

In addition to its omnipresence in the sphere of education, the complex language situation in Lebanon also finds itself reflected in the linguistic landscape. The languages that are used in public space in Beirut are predominantly Arabic, French and English, with a number of other languages in the minority. This means that one's eyes feast on a display of writing in two different scripts: Arabic, written from right to left in one alphabet and French and English written from left to right in another. There are also two different numeral systems (Western "Arabic" numerals that we know in the West "0, 1, 2, 3..." and the Eastern "Arabic-Indic" numerals that have a distinct graphic quality to them ". I $r$ r"). Whereas official signage in some capital cities of the world could reflect a regulated multilingualism with all information structured regularly in two or more national languages with each language expressing equivalent meaning, Beirut LL's is much less predictable. In some formal contexts such as highway signage, official building inscriptions or monumental façades, one can find bilingual or trilingual equivalence, but the overwhelming majority of the LL uses different languages and scripts to communicate different kinds of messages. The mixing of languages and scripts might be thought to exist for different audiences-such as in districts where there are many foreigners-but overall I believe that Beirut's LL assumes a multilingual, multiscript literacy of those who inhabit it. 
We might go so far as to call Beirut's LL chaotic. It is possible, after all, to see signage written in both Arabic and Latin script together, each language conveying different information. To make things more complex, the Arabic language can be written either with Arabic letters or using the Latin alphabet. Western languages are usually written with the Latin alphabet, but in older samples of signage (through the back streets of Hamra, for example) one finds transliteration into Arabic script. Furthermore, language samples in Arabic script can be accompanied by either numeral system, but English writing is typically found with the Western "Arabic" numerals only.
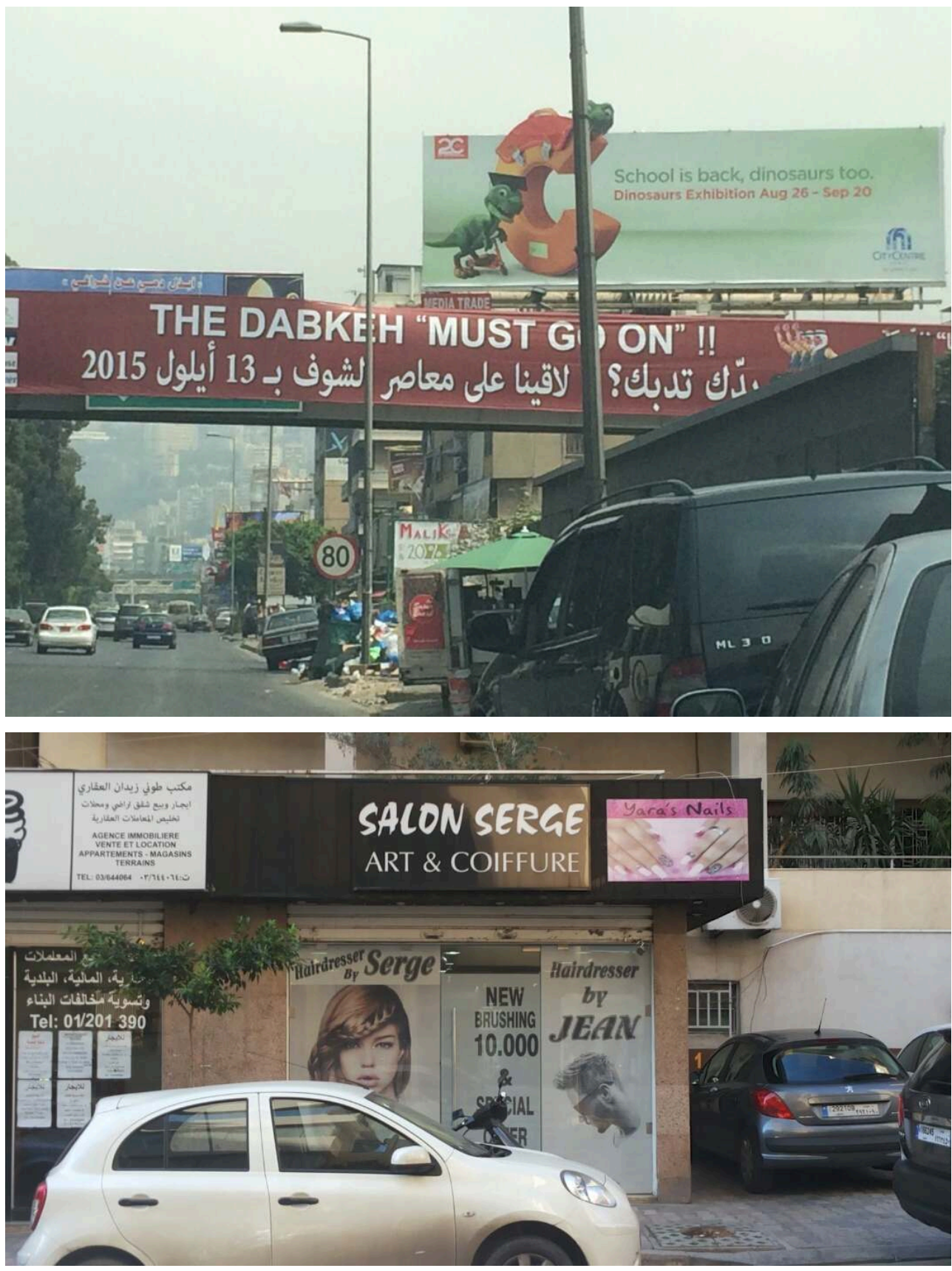


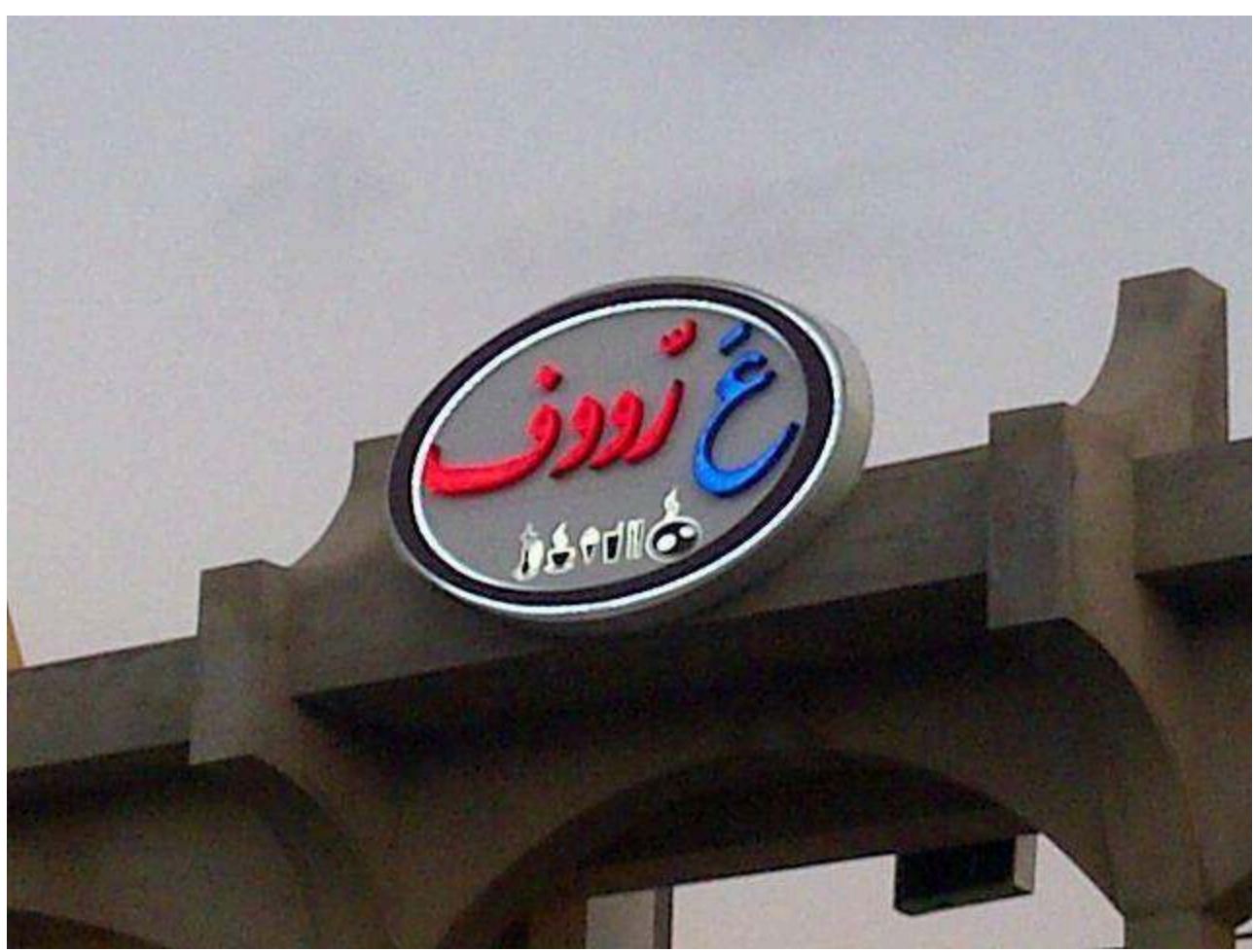

FIgURE 1 - Three sample photos from the "Linguistic Landscapes of Beirut" (LLB) project. A temporary banner hung across a highway bridge in Bourj Hammoud (left) announcing a traditional dance festival in both English and Lebanese Arabic; the storefront of a hair salon in Hazmieh using a characteristic mixture of English and French found in the health and beauty sector (center); the sign for a café in Saida imitating tendencies in spoken Lebanese Arabic to combine dialectal forms of Arabic prepositions "on the" with English nouns "roof" (right).

6 Figure 1 illustrates some different combinations of languages found in the data of the Linguistic Landscapes of Beirut (LLB) project. An example of Western words transcribed into Arabic script can be found in the image at far right where the word "roof" is written "رووف." The opposite phenomenon, namely Arabic words written in the Latin alphabet, a phenomenon known as "Romanized" Arabic or "Arabizi" is increasingly found in the society. Arabizi (sometimes also written "3rabizi") denotes a way of transcribing dialectal Arabic using Romanization that is quite popular around the Arab world, particularly in social media. It is a phoneme-to-grapheme mapping, drawing upon letters in the Latin alphabet with the same sounds. The linguistic samples in Figure 2 (below) contain what are called arithmographemes (Bianchi, 2012: 90). When Arabic phonemes have no equivalent in the Latin alphabet, numbers can be used instead. For example, the number " 3 " replaces the letter " $\varepsilon$ " in Arabic that is not present in Latin alphabets (Palfreyman \& al-Khalil, 2003; Al-Badrashiny M. et al., 2014; Bou Tanios, 2016).

7 The examples of Arabizi mentioned above are now common in urban space and quite catchy, lending a local, even informal, feel to the places that use them. The reasons for the rise of this "ASCII-ized" form of dialectal Arabic are to be found in the adoption of modes of computer-aided communication, such as messaging and social media, at a time when commonly used devices were not yet adapted to the Arabic language (Bou Tanios, 2016: 11-13; Palfreyman \& al-Khalil, 2003; Yaghan, 2008). It was only a matter of time before this "social media speak" made its appearance in the LL; at the time of the data collection for the LLB project, Arabizi was already a commonly found feature in 
the streets. Using examples such as those found in Figures 1 and 2, we can document how a layered, postcolonial city such as Beirut sketches and re-sketches its cultural identity using written language in its streets. To study the LL and the mixtures of language and script that appear therein is to access some of the processes of "complex sociolinguistics" in twenty-first century Lebanon (Blommaert, 2013: 27-30).
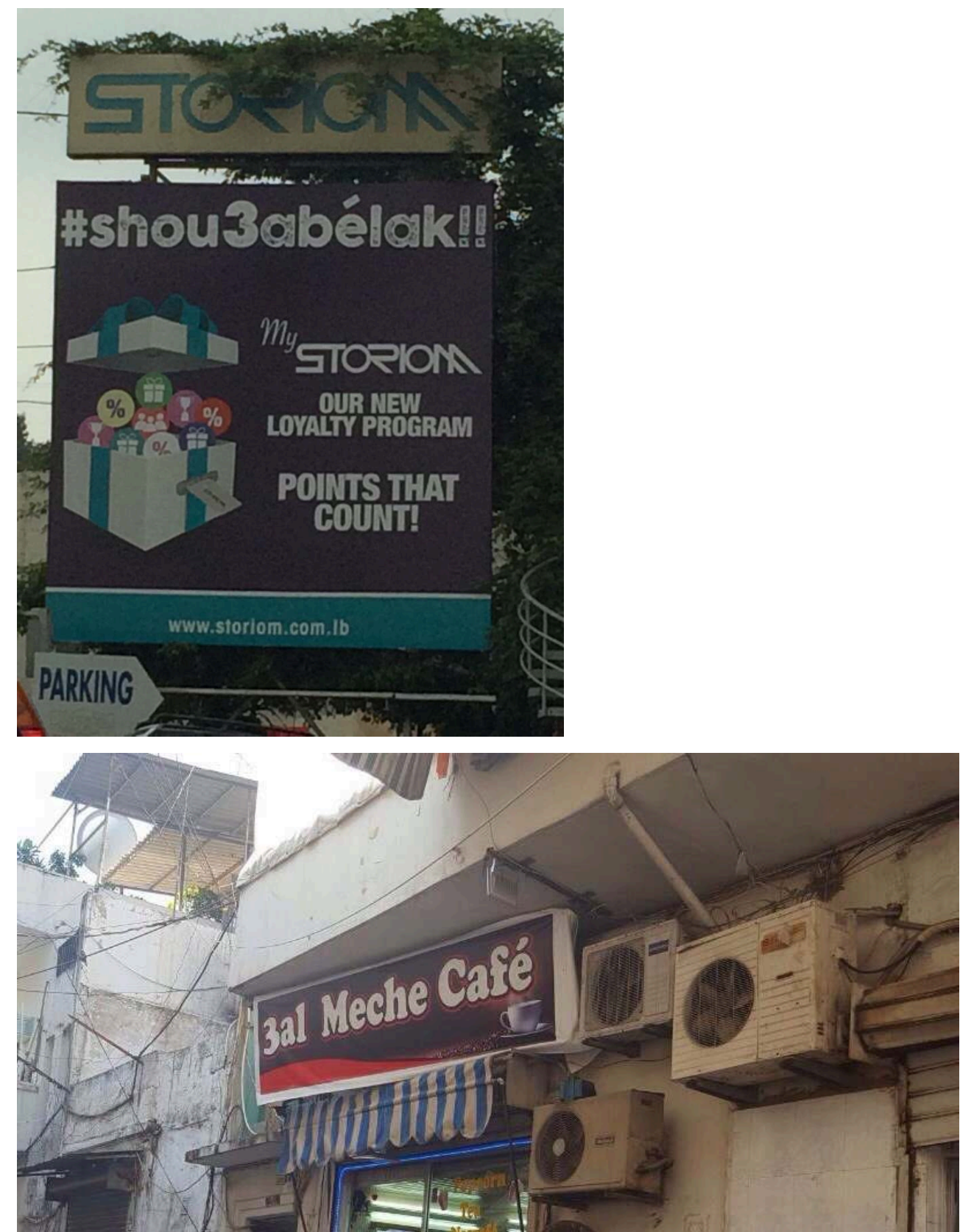

FIgURE 2 - Two sample photos of Arabizi in the streets of metropolitan Beirut. A shopping center's loyalty points program advertisement (left) with a hashtag "\#shou3abélak" ("شو عبالك"), a colloquia expression meaning something like "What do you want?" or "What's your fancy?" and a coffee shop (right) named "3al Meche Café" ("عالماشي" or "Take-Away Café") offering coffee to go.

8 This article focuses on a DH project that aimed to understand if Beirut's LL were indeed only chaotic, or if there were patterns to its complexity. Using a group-sourced data collection method and geospatial tools in a university course during the 2015-2016 university year, the LLB project collected some 3,000 samples of language in greater Beirut. ${ }^{1}$ The project adopted methods from LL studies, spatial humanities and DH 
pedagogy. Project participants took photos around the city using a mobile data collection application for smartphones (Fulcrum), they designed the metadata that they believed best represented the local linguistic situation, they tagged the individual photos that they took, they made maps of these photos using the geotags that the application created, and finally, they curated individual interpretative essays from the collective dataset.

As a digital humanities project in an Arab country carried out in 2015-2016, I believe that LLB was important for four main reasons. First of all, LLB had no local precedent at the time. To our knowledge, there were no other large local LL studies taking place simultaneously. The marriage of content and method came about rather organically from course modules on global English that overlapped with discussions about the language in the city and an exploration of digital methods. Second, LLB adopted its methods from projects taking place far away, rather than from any methods proposed within our university or national research infrastructure. Third, LLB did not work with pre-existing data, but rather created its own data "in the field." Lastly, the technical transparency of its workflow enabled the data collection to be scaled rather quickly, producing significant results in less than one year. Like any digital humanities project, it was difficult to know if or when it was finished. Instead of a clear demarcation-say, amount of data or duration of funding-LLB ended when I left my academic position in Beirut for another one. Nonetheless, it can be considered a successful project in as much as it blended theory, practice and pedagogy (Risam, 2019) in the spirit of scholarly inquiry and experimentation in a part of the world where digital knowledge production has been, and continues to be, a less than straightforward endeavor.

\section{Language Varieties, Language Mixing and Technology}

The LLB project came about as a result of a few years of experimentation with different ways of collecting and curating multilingual language samples in Beirut. Its genesis was less of a clear planning process than an organic evolution towards blending content and method. I received a faculty teaching release sub-award from a Mellon Grant for Curricular Innovation at the American University of Beirut in Fall 2012 for the purpose of exploring digital humanities methodologies in teaching and research. At the same time, as Chair of the Department of English, I was leading the faculty in a project of updating its curriculum to reflect the changing nature of English Studies. This did not mean only adopting theories from the outside, but aimed to build meaningful bridges between global theoretical trends and site-specific reflection from our location in the one of the Arab world's main cultural capitals. In reality this meant combining different varieties of world, transnational and diasporic literatures with courses in gender, media and digital humanities to the English curriculum, and attempting where possible to link those to real opportunities for undergraduate research.

11 Another subject that was revamped was the course, History of the English Language. This course had traditionally been taught as a survey of historical linguistics. Following other English departments in the Anglophone world, I sought to link this course both to the needs and interests of today's students and to local forms of knowledge (Williams, 2010). The new course's readings emphasized a cultural history of English with new modules on language contact, historical moments of standardization, the spread and 
change of English in the twenty-first century and a hands-on lab component focusing on the discovery of the history of English through linguistic data.

The course turned to digital resources such as the GLoWbE (Global Web-based English) corpus, and these provided us with a useful mirror to reexamine the geographic scope of English (Davies, 2013a). When we were using it in 2013, GLoWbE afforded a scaled insight into a wide range of world Englishes from countries such as India, Pakistan, Philippines, Singapore, Malaysia, Hong Kong, Nigeria and Ghana. These world Englishes reflect, on the one hand, a historic language situation impacted by English and American linguistic imperialism, but on the other, the results of the Google search engine of web-based English used by researchers to build the corpus (Davies, 2013b). One day a student in the course asked why no Arab countries had made it into the corpus, when English is widely used in large regional cities such as Beirut, Dubai or Cairo for daily communication. The simple answer to the student's question was no doubt a question of numbers; in the early 2010s the web content created in Arab countries in general, let alone in English, would not have returned many hits.

Here again we return to Risam's point about the nature of the digital cultural record, or simply web-based information, being curated in the Global North for the entire world. The student's question weighed heavily on my mind for two semesters teaching the subject, and it encouraged me to explore methods of documenting local English in contact. If Google did not return many instances of English in digital Lebanese space, we certainly had an abundance of English in our everyday urban environment. The genesis of the LLB project stems from the realization that the country and its ubiquitous language variation were themselves data sources that researchers could both observe and document. The LLB project came into being with the desire to revisit assumptions about multilingual realities in the Arab world that other research on Beirut's LL, on account of the research instrument itself, was not able to handle at scale (Karam et al., 2018; Farran, 2017).

\section{“Marhaba” Does Not End Where "Hello" Begins}

In Beirut's language situation, as we have mentioned above, there is a basic expectation of some literacy in Arabic, French and English, since it is rare to find written, public language that is trilingually equivalent. The LL resembles in this respect spoken Lebanese Arabic with a complex polyglossia. It is not uncommon, as Figure 1 above showed, to find competing languages, scripts and numerical systems that do not replicate meaning in the same sample. This detail points the fact that literacy in Beirut is highly contextual. My interest in documenting the LL in Beirut was based on a hunch that the variance was not random, but rather was rooted in a complex set of cultural values that local communities prioritized in different ways and in different locations.

To begin studying Beirut's LL as data, I embedded a microblogging exercise in the above-mentioned course on the history of language with the purpose of exploring language samples in the field. We established a basic methodology for our workflow: digital images should be taken or collected (of no particular provenance) and they should be classified with a small bounded set of tags and could optionally be described with small text blocks. These samples were posted to student Tumblr accounts, and a class Tumblr account was created to collect the most pertinent examples from individual student accounts (ENGL229 Tumblr, 2014). The coding was rather 
rudimentary in the beginning, including basic tags such as "mistranslation," "Arabizi," "wordplay," even "marketing." The exercise was a revealing one. Since no particular restriction had been placed on the origin of the language samples, students began to reblog other virtual materials, often of a parodic nature taken from other social media, diverting the project from the documentary process of our real life surroundings. I doubt that this was out of laziness or lack of interest in the assignment. Instead, the microblogging environment lent itself-in the very functionality of the application-to this kind of social media behavior. With this experiment in group curation of language samples, however, was born the idea of the LLB project.

Inspired by a discussion about whether the language samples we were collecting exhibited any spatial patterning, I remember exploring-without any particular success -the possibility of a workflow for extracting Tumblr postings in order to locate them on a map. The basic problem revealed the flaw in our original method: how to locate the geographic contexts of digital images if social media platforms systematically scrub EXIF data from uploaded image (EXIF is a data file created with digital images containing information about the camera, but also the location where the image was taken). At the end of the semester, one of my students carried out a final project that resembled a classic LL mapping exercise of some parts of the Hamra neighborhood near the American University of Beirut. The original student blog is no longer hosted, but screen shots are available in the Wayback Machine (Khezaya, 2014). The student's original hypothesis was that the immediate neighborhood of the university would be English dominant and that once leaving the perimeter of the neighborhood, Arabic would resume prominence. This hypothesis inspired a headline of a short article in the local English newspaper written about the student project: "Where Does 'Marhaba' End and 'Hello' Begin?" (Lutz, 2014) ["Marhaba" is an Arabic greeting, similar to hello in Lebanon]. The student's original hypothesis was based on language opinion about linguistic landscapes as having borders (by sect, neighborhood, etc.) and turned out to be wrong, but the idea of applying linguistic landscaping at different levels was an excellent one. Instead of strict borders, the student's findings were that the LL of Hamra is stratified by class, with languages and scripts intermingling much more than she had previously noticed. Whereas main streets are corridors of privilege and mobility, and in Hamra this meant a dominance of English, she argued the LL "ages" and becomes more Arabic/French the more one penetrates into the back, lesser travelled streets of the neighborhood.

\section{New Workflows Enabling Scaled Knowledge Production}

The problem of scalability loomed large at the end of this individual project; the work of data collection and entry to make the digital maps was very time consuming, indeed. It mirrored other studies about the Beirut LL that have been generally limited to a small number of streets or to wealthy, commercial neighborhoods such as Hamra or the city center (Karam et al., 2018; Farran, 2017). The granularity of Khezaya's data was also coarser than one might desire; furthermore, her experiment was not reproducible, that is, the data were not made available to others for reflection, reconsideration or verification. The research question that emerged from these multiple semesters of thinking about written language in Lebanon with my students might be stated as such: 
how can empirical sampling techniques document and analyze the fluidity and complexity of the linguistic landscape in Beirut, while documenting its language, script and numeral systems? The next step was to devise how to scale the documentation of the linguistic landscape in order to explore larger scale patterns. Ethnographic insight into why someone chose one language over another was not excluded, but was not the part of the basic research instrument.

The next quantum leap in thinking about how to study Beirut's language situation came about by pure chance, on the other side of the globe, and in the context of one of the "methodological dialogues" characteristic of digital humanities communities. The technical know-how of carrying out the new phase of the project became clear in Spring 2015-not as the result of local innovation in Lebanon-but through the chance meeting at New York University's Bobst Library with a group that was presenting the project "Art and Politics in the City" using some cutting-edge methods in Geographic Information Services (GIS) to map graffiti in Buenos Aires, Argentina. Mobile data collection was being used for what the NYU scholars called "culture mapping," and for us in Beirut the technique was a near perfect fit. Equipped with a new methodology-a form builder application for mobile data collection-we were ready to embark on the "typical linguistic landscape method of collecting photographical data" (Gorker, 2013: 205), but also to collect consistent metadata, all organized in a structured Postgres database that was managed by a third party service. I set out to design the new research instrument for deployment in the Fall 2015 semester that would allow for group collection of data, integration of geotagged images and extensive user-defined and -inputted linguistic metadata. This workflow was not without its shortcomingsthe largest being that the management of the database was not in our own hands-but it was far superior to previous attempts. It has been so effective that since 2015 I have used it in other cities of the world and in combination with other methods to explore the spatial distribution of cultural phenomena (Wrisley, 2015; Wrisley et al., 2017). There are other commercial applications that make such an urban data collection project possible, namely Survey123 (by ArcGIS) that also do not require internet connectivity in the field. Smartphone application environments are notorious, however, for requiring significant updating and technical maintenance. I have not yet found an application in the Free and Open Source Software (FOSS) domain that handles digital photography, metadata and geloocation with ease, although with the methodology gaining both interest and importance, there will no doubt be one available in open source version sometime soon. 


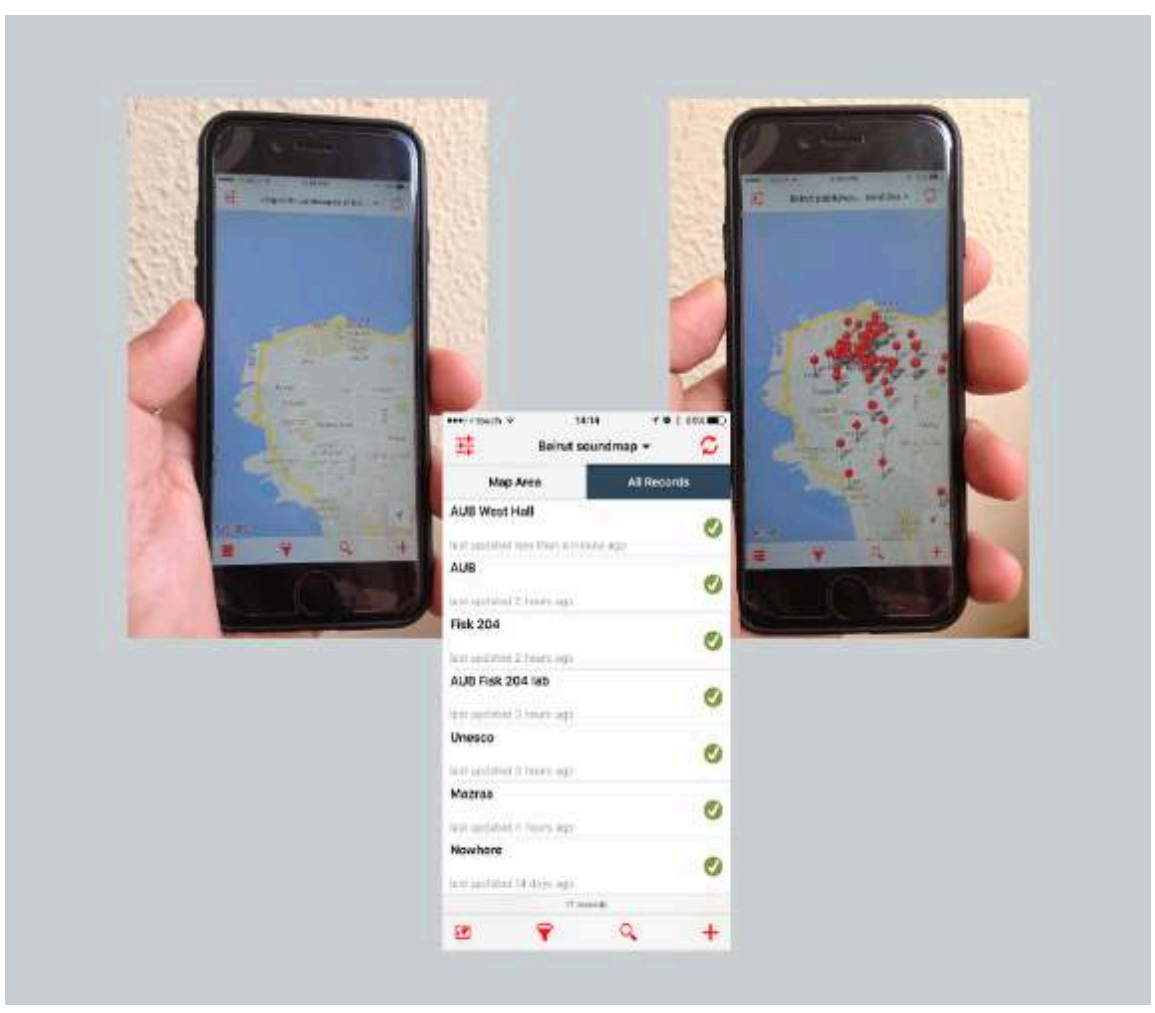

FIgURE 3 - Screenshots of the interface for mobile data collection with Fulcrum (fulcrumapp.org) for the Linguistic Landscapes of Beirut (LLB) project, including both the data entry form, as well as an empty map interface (left) and the map as it would look to project participants in the middle of data collection (right).

What we were doing over the year that followed was not crowdsourcing per se, but a kind of "group collection" of data. While it is true that the thirty some participants were able to "out-perform individual experts, [and] outsiders [to] bring fresh insights" to the LLB project, the participants were students of language and literature and not truly from the general public (Brabham, 2013). Upon the completion of our collective design of the coding schema for the samples that came out of discussions in the course, we began data collection. In the application template, participants assigned every image that was taken in the streets a certain amount of metadata on the fly: languages used, scripts used, general context of the image (e.g., signage, advertising, merchandise, health/beauty, food/entertainment) as well as any narrative comments they wanted to add. The structured database was available for us to use in real time in the course. One of the main learning objectives of the course was for students to be able to learn to build, manipulate, query and map datasets created in their own surroundings in order to formulate hypotheses using data. The amount of data collection was not onerous, on average 5 images per week per person, with some difference in the amount of data collected by individual participants. The tasks that we were carrying out in the group can be described as variations of "knowledge discovery" and "distributed human-intelligence tasking" (Brabham, 2013).

The process of data collection embedded in a university course brought up, nonetheless, questions of fairness-about the labor involved in the dataset creation, the attribution of that labor, and more generally, the social contract of the classroom-that were being raised at the same time by other DH practitioners in the United States (Keralis, 2018). A "Student Collaborators' Bill of Rights," had been drafted at UCLA to 
outline best practices for collaborations with students, particularly if students "are not empowered to make critical decisions about the intellectual design of a project or a portion of a project" (UCLA HumTech, 2015). It is important to me that the work of the data collection in the LLB project was not onerous and the focus was perpetually on learning from data that we ourselves have created. The design of the project metadata was in the hands of Lebanese students, and so I did not have ethical concerns about labor in this project. Our experience working on the LLB uncovered one point about privacy not explicitly discussed in the UCLA Bill of Rights, however, a point that is particularly important for spatial humanities projects involving smartphones: any geotagged data collected by participants needs to be anonymized so as to protect their geo-privacy. It was obvious to us, upon analysis of the dataset, that some students collected data in the immediate vicinity of their homes.

Since the methodology allowed us to scale the data collection across the period of one year, some interesting conclusions emerged from the project about the larger picture of Beirut's LL. We seem to have discovered spatial patterns of where the use of dual numeral systems seems to be abating in some particular northern suburbs. In addition, there are very clear clusters of minority language usage in the LL, such as in the Bourj Hammoud neighborhood with Armenian script. Perhaps the most important conclusion that we can draw doing such digital linguistic landscaping is that multilingualism is not only alive and well in Beirut (you could know this without digital methods), but that certain multilingual pairs are also predominant in particular sectarian enclaves in the city. Our main research question that we matched with the particular technologygeolocating smartphones-concerned the spatial patterning of particular language or script samples in the city of Beirut. It became increasingly clear is that LL data in Beirut is not always spatially significant, but often is contextually so. This means that the multilingual patterns of certain commercial sectors can be the same, independent of their location in the city. Much more analysis of the data needs to carried out, considering the spatial metadata as one part of multivariate analysis, rather than only relying on of map based visualization.

\section{What Makes a Digital Humanities (or Spatial Humanities) Project Visible?}

At the time of writing this article, the "Linguistic Landscapes of Beirut" (LLB) project is one of the few larger scale digital research projects carried out in the 2010s in Lebanon that has become known globally as a "digital humanities" or a "spatial humanities" project. We must be careful, however, in asserting the novelty of its digital research at a regional level, and this for the simple reason that the LLB project came into being when other centers for digital research and publications began emerging in the country (Mourad, 2014). There are no doubt other projects that have not gained international notoriety. That it bears the label of a DH project has more to do with the lead researcher involved, his connectivity to Euro-American discourses about the digital turn in the humanities and his adoption of that term, than with any particular local (Lebanese) trend in digital research.

The LLB project resembles previous LL research with a strong geospatial element. The superdiversity of the neighborhood of Stazione Termini, Rome's main train station, for example, was the object of one of a series of fascinating LL research projects based on 
immigrant and minority languages in Italy (Gorker, 2007; Barni \& Bagna, 2008). Why then have these LL projects not been hailed as early DH projects? Allow me to offer some potential reasons why LL research has rarely been included among global digital humanities projects. There are five reasons, in my opinion, that have mainly to do with the media employed and the social quality of the research. First, and perhaps easiest, early LL projects probably emerged before the notion of the digital humanities project had gained notoriety in the global academy. Second, the projects were not disseminated via the web, but instead in traditional academic publishing that can curtail wide, public exposure to the research (Many other examples of DH-like work no doubt exist that are not well known on account of their limited visibility.) Third, the LL studies of Barni and Bagna were, no doubt, the product of a whole social effort of data collection, but, as is the case with much LL research, the collective effort of data creation were not made public. One of the tenets of a critical feminist digital humanities, laid out by D'Ignazio and Klein, is that the labor of digital humanities projects must be revealed, that is, it must be broken down, attributed and made public so that the complexity of the project can be understood and the various participants in it can be acknowledged (2017: 3). By giving credit to all those that participated in a project such as LLB, as I have done in this paper and on the project site, we are able to grasp how it has emerged as social knowledge.

Fourth, non-interactive, early GIS-based maps of the kind we find in the abovementioned research are produced in a style that Edward Tufte has deemed "flatlands," that is, they have a two-dimensional quality that limits our aim to understand our world as "inevitably and happily multivariate in nature." (1900: 12) The LLB project sought, on the other hand, to create interactive, live objects allowing a deeper discovery of the linguistic situation from the map interface. To a limited extent, as shown in Figure 4 (below), the project achieved that goal by allowing the LL samples to appear on the map itself. Finally, and perhaps this is the most salient point for how the project became notable, the LLB project about linguistic diversity was designed in Beirut itself, took shape as a result of many conversations with Beirutis and was for some a point of national reflection and pride. The five reasons I have mentioned here point to some of the ways that the LLB project distinguishes itself from other LL research and might provide food for thought for LL projects in the future. They would certainly benefit from embracing a social, community approach, as well as taking advantage of the affordances of narrative, web-based GIS environments. Some recent work indicates that this transition is underway (Purschke, forthcoming). 


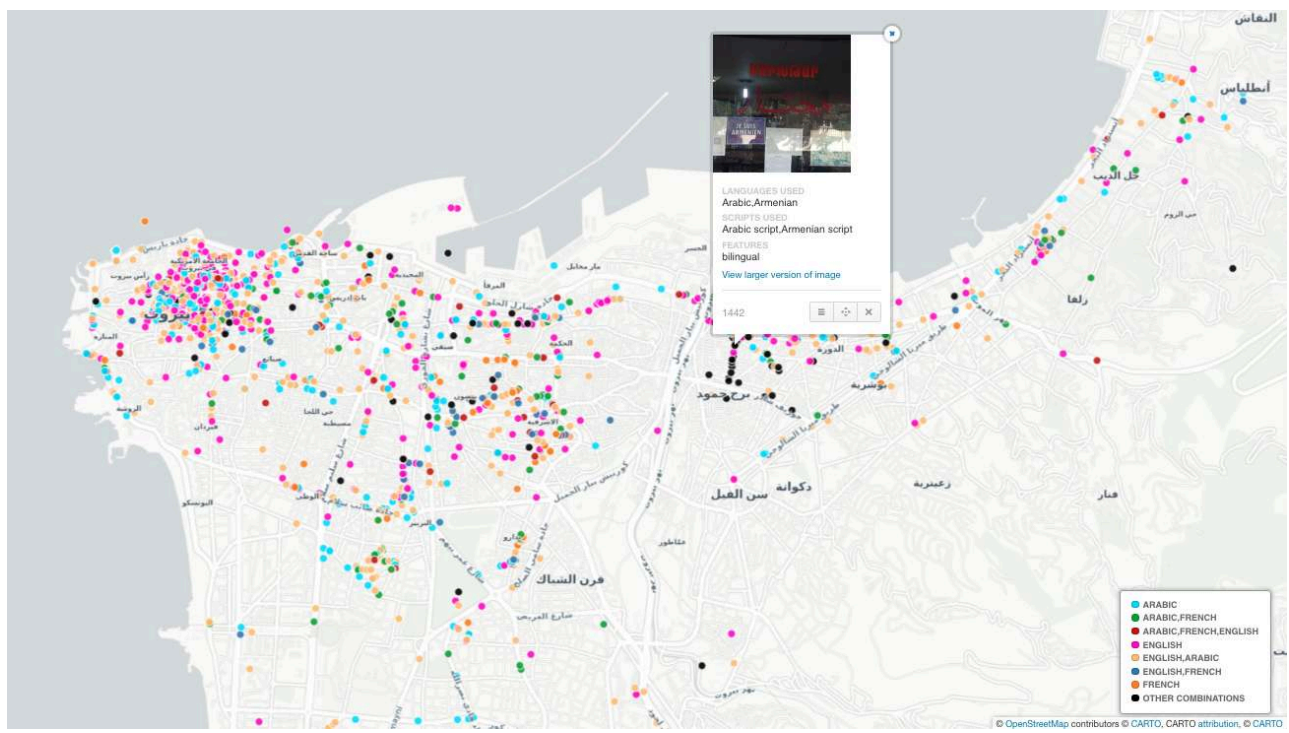

FIgURE 4 - A map where each point indicates a digital photograph taken of different multilingual samples of language in Beirut (with the bounding box of Antelias at the top right, the Beirut airport at the bottom left and the hills rising to Metn at the bottom right.) Color is indicative of the particular multilingual mixture. A pop-up infobox provides a sample image of Arabic and Armenian from the Bourj Hammoud neighborhood and some of the metadata associated with it.

There is an important element to the creation of the data in the LLB project that has not been underscored thus far. From searching for spatial patterns in language use, our goal expanded to creating maps that were exploratory and interactive, maps more akin to sound maps of cities that allow a sensory dive into urban space. Spatial humanities practitioners would point to the fact that, rather than making a simple map of Beirut's languages, we were "deep mapping" the linguistic landscape (Dunn, 2019). Deep mapping is simultaneously "a platform, a process and a product," or in other words, a critical engagement with technology to "trace pathways of discovery, framed as a conversation and not a statement" (Bodenhamer, 2015).

With time, the LLB project became infused with this conversation-like quality, in which multiple participants could be co-discovering and co-analyzing the multilingualism in their own city, and importantly, from neighborhoods that they may never even visit in real life. In this respect, the project also aspired to the goal of intercultural competence that some Western LL projects have espoused (Waliński, 2014). Of course, a key difference between Beirut and the Western cities where minority languages are studied is that variation and multilingualism are the norm across all neighborhoods of Beirut. The depth of the mapping project is not so much expressed by the quantity of data included in it, but by the complexity and the quality of the rich interactions that emerged from the process, as well as the ways in which participants re-contextualized the data in their own storytelling. The ability to see the data as they were being collected in the smartphone interface, shown above in Figure 3, as well as having access to the dynamic dataset as it grew and being able to learn from the data collection of others working on the project in real time were crucial elements of the process of learning and knowledge creation. This is an approach that Waliński identifies with "mlearning activities," linked to student mobility in space, but also to raising "cultural awareness through empirical hands-on exploration of the surrounding linguistic reality in a local environment" (2017: 1). This in situ fieldwork is increasingly found within 
social knowledge creation practices that develop and sharpen data literacy skills (Arbuckle et al., 2017).

\section{International Digital Humanities?}

One would expect that a digital research project conceived and carried out in Beirut, both by Beirutis and long-term residents, would be distinctive from a project about the city executed from outside the country. But what would exactly be the difference? The availability of first-hand research material, the ability to iterate over a city-archive without limitations of time or access, or a sensitivity to the complexity of the local environment would be significant benefits of a project elaborated "in situ." Let us pause for a moment to reflect on the term "international" that frames the contributions to this special issue. The literal meaning of the word connotes an inbetweenness with respect to nations, dare I say, a mobility between territories. With the theme "An International Perspective on Digital Humanities," the editors of this special issue no doubt meant to draw attention to digital humanities projects that are not only carried out in the West about some far-flung part of the world, but also fledgling projects under way in the rest of the world, projects from which we all can learn and with which we can enter into dialogue. Looking at "international" DH therefore, provides us with insight into how DH are developing in parts of the world outside of a Western-only politics of knowledge and beyond the dominance of Englishspeaking countries. I would like to insist, however, that a negative definition of the term "international" as a far-away "other" is not fully productive for understanding how DH are appearing in the world, since the word "international" also connotes a cosmopolitan approach to the notion of culture extending beyond the strictures of the nation-state, embracing the possibility that knowledge and innovation resulting from digital humanities research can flow between global locales.

In their high-level definition for digital humanities (DH) practice, Dacos and Mounier highlight the "interdisciplinary dialogue on the digital dimension of research in the humanities and social sciences, at the level of tools, methods, objects of study and modes of communication." This definition is valuable in as much as it allows us to discuss the complex interdisciplinarity and innovative methods in the humanities without asserting national, regional or disciplinary dominance over their genealogies. It also allows us to avoid locating those digital practices within specific temporalities of emergence and in limited regions of the globe. The notion of "interdisciplinary dialogue" between researchers about tools and methods is also generative since it allows us to explore how methods can jump in time and space between research environments, as I argue elsewhere, often despite significant infrastructural difference in the parts of the world (Wrisley, 2019). Access to digital humanities training and pedagogy for a variety of knowledge situations, I argue, is a key element in this dialogue.

Lest we ignore the inequities of parts of the world such as in the Arab countries, in which stewardship of the digital cultural record is known to be underdeveloped, and where knowledge production has been characterized by some as "the impossible promise" (Hanafi \& Arvanitis, 2015) despite the rich cultural heritage to be studied, a necessary adjustment to the Dacos-Mounier definition of DH can be found in the project of inscribing postcolonial critique within digital knowledge production. Risam 
argues that the digital cultural record is "in danger of telling the story of humanity from the perspective of the Global North alone" (2019: 6). Curating the cultural record from sites other than Euro-American archives and universities seems to us one key way to resist against a new global order of digital knowledge. Digital humanities practices draw upon methods and toolkits shared across different globalized contexts, but they can also construct their "objects of study" against the grain, as they blend different methods. If digital humanities can be said to have an accent in different parts of the world (Risam, 2019: 79), can they not also be said to code-switch in ways that are perhaps disruptive to Euro-American sensibilities?

One way that the LLB project can be said to disrupt a key narrative of the rise of DH in the Euro-American world is how it circumvents the notion that digital humanities emerges from the methods of humanities computing, the field that used computation to work with textual data. It has been argued that this context does not apply to the variety of scenarios of global DH (Sneha, 2016). In fact, the LLB project did not begin as a project about textual data, but rather with a group-sourced collection of geotagged images taken in the street. While it is true that the visual data contained samples of language in them, our analysis of the samples was not based on any kind of granular text mining or word frequency counts. Instead, our analysis focused on spatial patterns within the metadata created about the images on the fly during data collection. It differed from a corpus building exercise where a number of archival or printed texts would be remediated into a machine-readable format for computational analysis. We have considered extracting the text from the images for such analysis, but this step entails a significant amount of labor and will have to take place at a later date.

\section{Social and Infrastructural Challenges}

31 Looking back on the year's experimentation with some distance, it is obvious to me what some of the infrastructural and social challenges of the project were. Unexpected issues with the social data collection process included the fact that different brands, models and settings of phones created an image dataset of varied sizes, weights and orientations. In the beginning we set minimal constraints on the data collection process, meaning that any kind of linguistic phenomenon could be documented. Pictures including people or the government or army buildings were strictly forbidden. This rule was set up (but not always respected) largely with social mores and realities of the Arab world in mind. Given that the context of research in the contemporary Arab world is a sensitive one, particularly working in an American university when the lead researcher is an American national, some social science researchers adopt a "fly-onthe-wall" approach. Yet, such a well-meaning approach to field research "runs afoul of its own simplicity because even taking photographs and leaving footprints can be political acts" (Carapico, 2006: 429).

One of the distinctive features of the Beirut LL is decidedly the difficulty with which it is photographed. Photography is a sensitive topic in majority Muslim cultures, in general, and in post-war environments hypersensitive to surveillance like Lebanon (Najem \& Bitar, 2016). Since our project's goal was to create image data about the LL across Beirut for analysis and reuse, this meant that we were taking pictures with smartphones in parts of town not frequented by tourists where picture-taking is a common practice. While the intention of the project was scholarly and linguistic, it 
struck some people as odd, and even, potentially inappropriate. Initially, students felt uncomfortable that their data collection could be misconstrued, but soon they came up with their own best practices for non-invasive data capture: such as feigning a selfietaking pose, but actually taking a picture in the opposite direction, or taking pictures from within their cars, at night or upclose.

As we began to explore the data in the aggregate, two very interesting elements emerged. First of all, we compared the data collected in the LLB project with maps that colleagues in urban studies in the Department of Architecture and Design of the same university had made of what they call the "visible security mechanisms of municipal Beirut." With these maps of checkpoints, private security booths, barbed wire and police, the authors point to elements of the cityscape-recognizable to anyone who visits, lives in or simply tries to move around in Beirut-as the signs of a sense of insecurity and desire to "[protect] key political figures and/or [prevent] intercommunal violence" (Fawaz et al., 2010). What we found should have not surprised us, but most of the data collected did not fall within the areas of these private and public security mechanisms. That so many pictures were taken in the Hamra neighborhood, I believe, was not only due to the proximity to the university or to the relative social openness of the neighborhood, but rather due to its location between the visible security mechanisms. If we extrapolate from this finding, not only are the stakes of digital research in a country like Lebanon potentially very high, but the ability to access materials for scholarly purposes is limited by the infrastructural reality of the country. An essential element to all postcolonial digital pedagogy lies in understanding how world powers have shaped knowledge of the past and its aporia (Risam, 2019: 90). It follows, however, that in a postcolonial present, data created now is neither abstracted from the situation of the country, nor the agency of the creators. How should digital humanities in a weak state like Lebanon position itself with respect to knowledge production, in the face of calls from Western countries to access and openness, when such values are difficult, even dangerous, to embrace in the local knowledge environment?

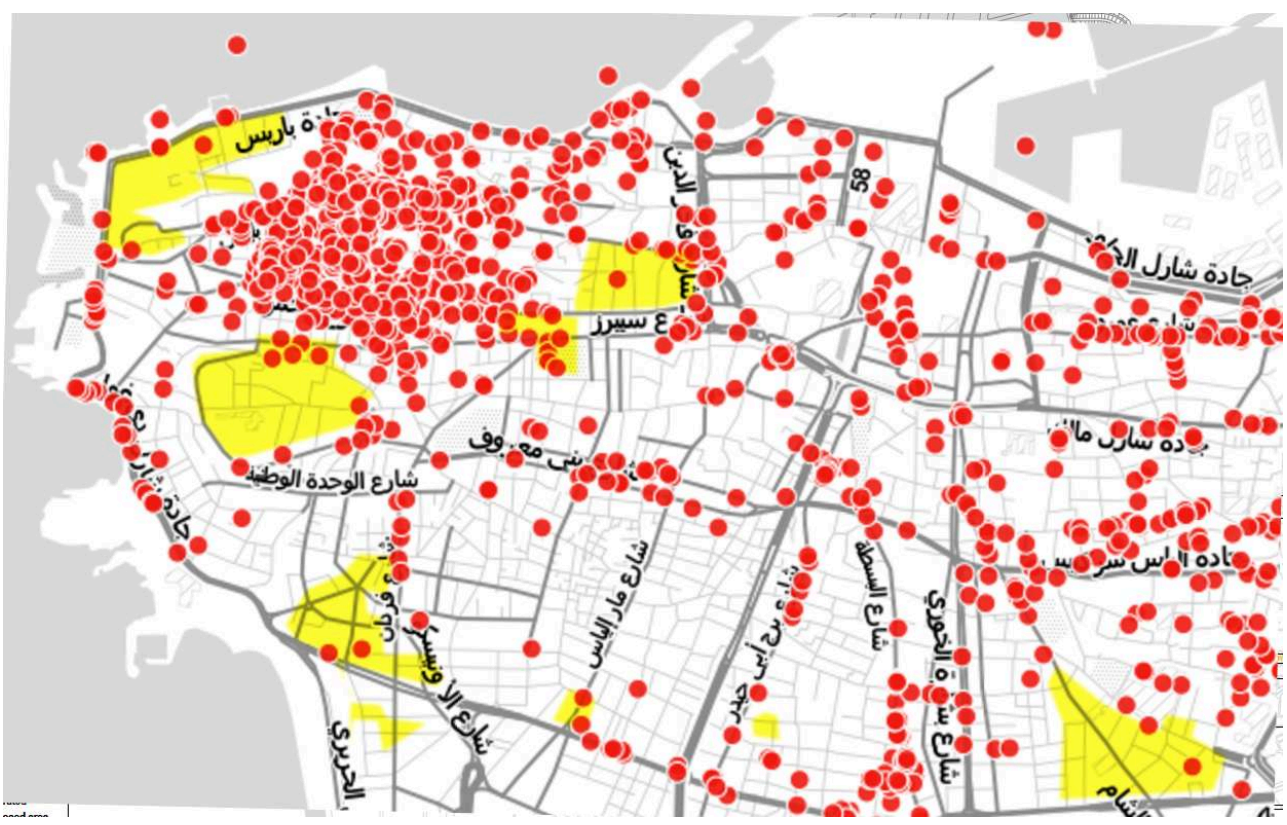

FIgURE 5 - The aggregate of data samples in the LLB project taken in 2015-2016 (in red) overlaid onto simple polygons (yellow) extracted from the maps published by Fawaz et al. showing the visible security mechanisms of Beirut in 2009. Credit for the polygons: Mario Hawat. 
ecent years, it has grown increasingly interesting to me to analyze the data from the LLB project "off the map." While a map allows us to visualize the points of data capture as a spatial phenomenon, it does not allow us to understand them in relation with other complex data. Much more multivariate analysis needs to be done about the contextual use of language, which as we mentioned above, is not a purely spatial phenomenon. This would push our understanding in a Tuftian direction, "escaping flatlands," towards an understanding that could hopefully be reimported into a visual environment more complex than a GIS-based map.

In another analysis carried out on the aggregate of the LLB project's photographic data, some interesting patterns can be seen as well (Figure 6). Color scale analysis of the photos suggest that there were, in fact, many photographs taken of language samples up close and with little surrounding context (notice the largely white and grey images at center right of Figure 6). The images containing bright clear shades of blue (bottom center) combine official signage with pictures taken outside on clear, sunny days. Note that there are very few of these pictures taken. There is a small neutral beige-like center to the image plot that illustrates the kinds of sandstone used in the facades of buildings in Beirut. On the other hand, at least half of the images are dark to black (at center left)-almost certainly pictures taken at night-or red from indoor lighting or mercury-vapor street lighting. The main question that arose from this distant analysis of the images is why were so many pictures for the project taken in the dark, closeup or indoors? Is this a random observation, or another indication that image data was gathered in a photography-unfriendly environment? More analysis is no doubt needed to tell for sure.

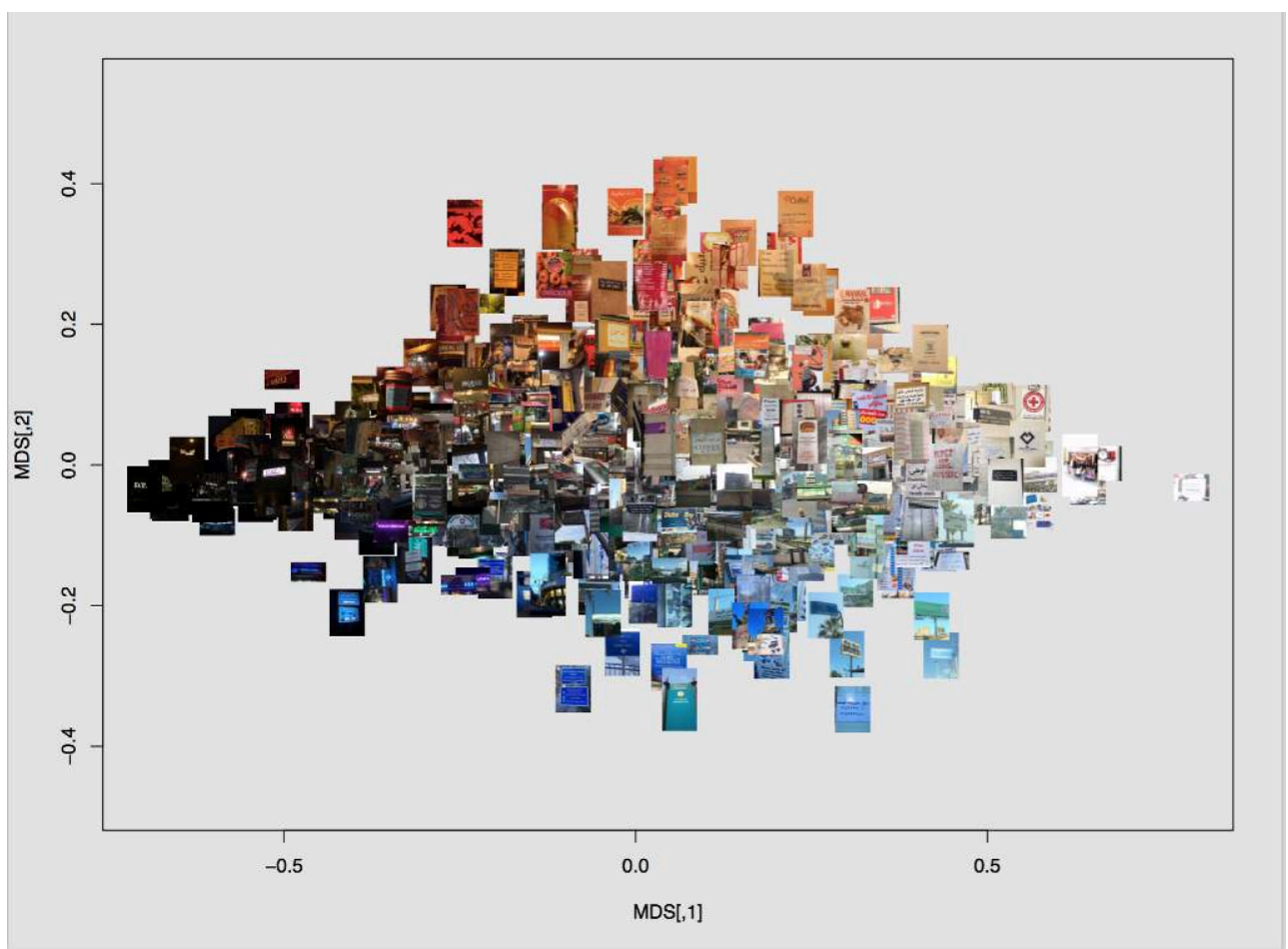

FIgURE 6 - A scatterplot of raster images from the LLB project, created by averaging the RGB values of $2800+$ images, applying multidimensional scaling in $\mathrm{R}$. The $\mathrm{x}$ axis reflects a gradient from black to white (left to right) and the y axis red to blue (top to bottom). Code adapted from Sparks (2012). 


\section{Conclusion}

Beirut is a space of assumed multilingualism. But what multilingualism(s) and created by whom? These questions are what the Linguistic Landscapes of Beirut (LLB) project set out to explore. Beirut is a contested, and complex, urban environment with an atmosphere that can reach levels of unsettling tension and insecurity. From an LL perspective, Beirut contains many linguistic and sociolinguistic factors that make its analysis both desirable and challenging. Its case is perhaps less singular than it may seem, if we take into consideration other countries with non-Latin scripts in Africa, the Balkans, the Indian subcontinent and the Arabian peninsula. On this point, like in Beirut, one may be able to study world Englishes in contact in ways that are not documented by corpora collections in the global North. The LLB project did not attempt to resolve all of the complexities of its environment (linguistic or social), but rather to take a larger, birds eye view of the language situation using digital technologies. We cannot say that the LLB project is exemplary of a class of projects taking place in the Arab world, for the simple reason that digital humanities research is really only incipient in the region at the time of writing this article. The LLB project provides an excellent case study, however, for how granular, digital linguistic documentation might extend beyond studying select minority neighborhoods of the largely regulated landscapes of Western cities to include historically layered, multilingual international locations. As a digital humanities project that took root at a moment of underresourced infrastructure and the beginning of interest in digital humanities research in the region, the LLB project ultimately embodied in its data a habitus, characteristic elements of the complex process of carrying out research in Beirut. As it has been argued, "computation changes research," but I think we must also respond that context changes computational research (Foster, 2011). We realized this fact as we documented and analyzed both the process and product of the project. A recent reviewer commented about LL research in general that "all 'languaging', through the nature and necessity of the spatiality of language, happens in a specific place," but suggests that detailed sociolinguistic study must also be rooted in landscape (Nash, 2016). Beginning with the "shallow" mapping of GIS of tracing a frequency of a phenomenon in geographic space-especially for multicultural, urban environments-the analyses of the LLB project, its data, its participants and its emergence in the institution, have attempted to provide a deeper landscape in which to see Lebanese multilingualism.

\section{BIBLIOGRAPHY}

ARbuCKLe Alyssa, MAURo Aaron, \& Powell Daniel [eds] (2017), Social Knowledge Creation in the Humanities, Toronto, Canada: Iter Press.

AL-BADRASHINY Mohamed, EsKANDER Ramy, HABASH Nizar, \& RAMBow Owen (2014), “Automatic Transliteration of Romanized Dialectal Arabic", Proceedings of the Eighteenth Conference on Computational Language Learning, Baltimore, Maryland, USA, 30-38. 
BARNI Monica (2006), "From Statistical to Geolinguistic Data: Mapping and Measuring Linguistic Diversity", FEEM Working Paper, 53(06), <http://dx.doi.org/10.2139/ssrn.896668>.

Bianchi Robert Michael (2012), “3arabizi - When Local Arabic Meets Global English”, Acta Linguistica Asiatica, 2(1), 89-100.

BlOMMAERT Jan (2013), Ethnography, Superdiversity and Linguistic Landscapes: Chronicles of Complexity, Bristol (UK) - Buffalo - Toronto: Multilingual Matters.

Bou TANIOS Jennifer (2016), Language Choice and Romanization Online by Lebanese Arabic Speakers (MA Thesis), Universitat Pompeu Fabra, Barcelona.

BRABHAM Daren C. (2013), Crowdsourcing, Cambridge, Massachusetts: MIT Press.

CARAPICO Sheila (2006), "No Easy Answers: The Ethics of Field Research in the Arab World", PS: Political Science \& Politics 39 (3), 429-31.

DAVIES Mark (2013), “Corpus of Global Web-Based English: 1.9 billion Words from Speakers in 20 countries (GloWbE)", online at English-Corpora.org: <https://www.english-corpora.org/glowbe/> (May 1, 2019).

DAVIES Mark (2013), "Introducing the 1.9 Billion Word Global Web-Based English Corpus (GloWbE)", online at English-Corpora.org: <https://21centurytext.wordpress.com/introducingthe-1-9-billion-word-global-web-based-english-corpus-glowbe/> (May 1, 2019).

D’IGNAzIo Catherine \& KLEIN Lauren F. (2016, October), “Feminist Data Visualization”, Proceedings of 1st Workshop VIS4DH Visualization for the Digital Humanities (IEEE Vis), Baltimore, Maryland, $<$ http://vis4dh.dbvis.de/2016.html\#papers> (May 1, 2019).

EsSEILI Fatima (2014), “English Language Teaching in Lebanese Schools”, K. M. Bailey \& R. M. Damerow (eds), Teaching and Learning English in the Arabic-Speaking World, New York / Abingdon, UK: Routledge, 101-14.

FARRAN Ziad Zouheir (2017), The Linguistic Landscape of Hamra, Beirut (MA Thesis), American University of Beirut, Lebanon.

FAWAZ Mona, GHARBIEH Ahmad, \& HARB Mona [eds] (2009), “Beirut: Mapping Security”, DIWAN publications, International Architecture Biennial of Rotterdam (IABR), <https:// www.academia.edu/9224504/BEIRUT_MAPPING_SECURITY_> (May 1, 2019).

FOSTER Ian (2011), “Computation Changes Research”, T. Bartscherer \& R. Coover (eds), Switching Codes: Thinking Through Digital Technology in the Humanities and the Arts, Chicago: University of Chicago Press, 15-37.

GHAITH Ghazi \& SHAABAN Kassim (1999), “Lebanon's Language-in-Education Policies: From Bilingualism to Trilingualism”, Language Problems and Language Planning, 23(1), 1-16.

HANAFI Sari \& ARVANITIS Rigas (2016), Knowledge Production in the Arab World: The Impossible Promise, New York / Abingdon, UK: Routledge.

KeZHAYA Alice (2014), “Language Borders: Linguistic Mapping in Beirut”, online on WordPress: <https://web.archive.org/web/20160127143313/https://alicekezhaya.wordpress.com/ 2014/07/08/language-borders-linguistic-mapping-in-beirut/> (May 1, 2019).

LANDRY Rodrigue \& BOURHIS Richard Y. (1997), "Linguistic Landscape and Ethnolinguistic Vitality: An Empirical Study", Journal of Language and Social Psychology, 16(1), 23-49.

CARAPICO Sheila (2006), "No Easy Answers: The Ethics of Field Research in the Arab World", PS:

Political Science \& Politics, 39(3), 429-31. 
LuTZ Maris (2014), “Where Does 'Marhaba' End, and 'Hello' Begin?”, online on The Daily Star: <http://www.dailystar.com.lb/News/Lebanon-News/2014/May-14/256436-where-does-marhabaend-and-hello-begin.ashx\#axzz31PTM1LVF>.

KARAM Fares J., WARREN Amber, KIBLER Amanda K., \& SHWEIRY Zinnia (2018), “Beiruti Linguistic Landscape: An Analysis of Private Store Fronts", International Journal of Multilingualism, 15(1), 1-19.

KERALIS Spencer (2018), “Disrupting Labor in Digital Humanities; or, The Classroom Is Not Your Crowd", D. Kim \& J. Stommel (eds), Disrupting the Digital Humanities, Goleta, Canada: Punctum Books, 273-94.

MOURAD Ghassan (2014), Digital Humanities: Natural Language Processing and Reflections on Technological Culture and a New Humanities [in Arabic], Beirut: All Prints.

NAJEM Mohamed \& BITAR Lara (2016), Mapping the Digital Surveillance Situation of Lebanon, Beirut: Social Media Exchange, <https://www.smex.org/wp-content/uploads/2016/12/SMEX-LandscapeMapping-of-Digital-Surveillance-in-Lebanon.pdf> (May 1, 2019).

NASH Joshua (2016), “Is Linguistic Landscape Necessary?”, Landscape Research, 41(3), 380-84, <doi.org/10.1080/01426397.2016.1152356>.

Palfreyman David \& Al-Khalil Muhamed (2003), “A Funky Language for Teenzz to Use: Representing Gulf Arabic in Instant Messaging”, Journal of Computer-Mediated Communication, 9, <https://doi.org/10.1111/j.1083-6101.2003.tb00355.x>.

PURSCHKE Christoph (forthcoming), "Using Crowdsourced Data to Explore the Linguistic Landscape of Cities. Results from the Participatory Research Project Lingscape", S. D. Brunn \& R. Kehrein (eds), Handbook of the Changing World Language Map, Heidelberg: Springer.

RISAm Roopika (2019), New Digital Worlds: Postcolonial Digital Humanities in Theory, Praxis and Pedagogy, Evanston, United States: Northwestern University Press.

SNEHA Puthiya Purayil (2016), "Mapping Digital Humanities in India”, online on CIS Papers: <https://cis-india.org/papers/mapping-digital-humanities-in-india> (May 1, 2019).

SPARKS D. (2012), "Flag Space: A Scatterplot of Raster Images", online on is.R(): <https://isr.tumblr.com/post/33700919594/flag-space-a-scatter-plot-of-raster-images> (May 1, 2019).

TRABOULSI Fawwaz (2007), A History of Modern Lebanon, London: Pluto Press.

TUFTE Edward (1990), Envisioning Information, Cheshire, England: Graphics Press.

UCLA HuMTECH (2015), A Student Collaborators' Bill of Rights, online on <https://humtech.ucla.edu/ news/a-student-collaborators-bill-of-rights/> (May 1, 2019).

WADDELL Kaveh (2017), “Mapping the Blurred Lines of Beirut's Many Languages”, online on CityLab: <https://www.citylab.com/design/2017/11/mapping-the-blurred-lines-of-beirutslanguages/546359/> (June 15, 2019).

WALIŃSKI Jacek (2014), “Developing Intercultural Competence with Linguistic Landscape \& MLearning”, M. Krawiec (ed.), Foreign Language Education and Its Cross-Cultural Links, Newcastle upon Tyne: Cambridge Scholars, 107-20.

WiLliams Tara (2010), “The Value of the History of the English Language Course for the TwentyFirst Century", Profession, 12, 165-76, <doi.org/10.1632/prof.2010.2010.1.165>.

WRISLEY David Joseph (2015), "Mapping Beirut Print Culture", American University of Beirut, Beirut, Lebanon, <https://mbpc.djwrisley.com/> (May 1, 2019). 
WRISLEY David Joseph (2019), "Enacting Open Scholarship in Transnational Contexts”, POP! Public, Open, Participatory (1), <http://popjournal.ca/issue01/wrisley>.

WRISLEY David Joseph, et al. (2016), Linguistic Landscapes of Beirut, online on: <http://llbeirut.org/> (May 1, 2019).

WRISLEY David Joseph, et al. (2014), "Featured on the Daily Star", online on ENGL229: <https:// engl229.tumblr.com/> (May 1, 2019).

Wrisley David Joseph, BAydAR Gulsum, HeRold Nastasia, AleKSIC Vladmir, GaGarinA

Dinara [...] NETZER Yael (2017), "Linguistic Landscapes of Leipzig [Data Set]", online on Zenodo: <http://doi.org/10.5281/zenodo.835491> (May 1, 2019).

Wrisley David Joseph, HAWAT Mario, \& RAHME Dalal (2017), “Creating Geotagged Humanities Data via Mobile Phone: Challenges and Opportunities", Proceedings of JADH conference, Faculty of Culture and Information Science, Doshisha University, Kyoto, Japan, 89-91.

YAGHAN Mohammad Ali (2008), “'Arabizi': A Contemporary Style of Arabic Slang”, Design Issues, $24(2), 39-52$.

\section{NOTES}

1. This work has been carried out in collaboration with former students at the American University of Beirut. The team and their roles are listed on the "Team" tag of the project website: $<\mathrm{http}$ ///llbeirut.org/>. The students in the course represented somewhat of a cross-section of contemporary Lebanese society, with differing levels of English dominant education. Most, but not all, of the students could read Arabic with native fluency. One student was proficient in Armenian. The course in which the project was embedded was reserved for students from the Department of English, specializing in either literature and language. Few of the students had prior advanced technical or computational skills. The LLB project was carefully planned so that students with little or no exposure to digital humanities methodologies could participate in the data creation, analysis and interpretation. Many of the insights contained in this article derived from our collective thinking. It would not have been possible without them.

\section{ABSTRACTS}

This article describes research done on language and script variation in the linguistic landscape (LL) of Beirut, Lebanon. It discusses how the cityscape itself became an archive for researchers and how digital humanities' (DH) methods were used to capture and analyze patterns in written language found in public space. It also discusses the DH project, Linguistic Landscapes of Beirut (LLB) at the heart of this research and the benefits and challenges of its two core methods: mobile data collection for documentation of linguistic diversity and geospatial visualization. The article argues that knowledge production in non-Western locations such as Beirut is both impacted and enriched by the complex political and social environment. This research, carried out with under-resourced infrastructures and at the frontiers of DH practice in the Arab world, 
blended theory, practice and pedagogy, ultimately illustrates that context profoundly changes computational research.

Cet article décrit des recherches effectuées sur la variation de la langue et de l'écriture dans le paysage linguistique (LL) de Beyrouth, au Liban. Il explique la façon dont le paysage urbain luimême est devenu une archive pour les chercheurs et celle dont les méthodes des humanités numériques (DH) ont été utilisées pour capturer et analyser les modèles du langage écrit dans l'espace public. Il aborde également le projet DH, Paysages linguistiques de Beyrouth (LLB) au cœur de cette recherche et les avantages et les défis de ses deux méthodes principales : la collecte mobile de données pour la documentation de la diversité linguistique et la visualisation géospatiale. L'article soutient que la production de connaissances dans des endroits non occidentaux comme Beyrouth est à la fois influencée et enrichie par un environnement politique et social complexe. Cette recherche, menée avec des infrastructures sous-financées et aux frontières des pratiques des humanités numériques dans le monde arabe, mêlant théorie, pratique et pédagogie, illustre finalement que le contexte change profondément la recherche informatisée.

\section{INDEX}

Mots-clés: sociolinguistique, variation linguistique, paysage linguistique, humanités numériques spatialisées, Beyrouth, Liban, langue arabe, géolinguistique, saisie mobile de données, polyglossie, crowdsourcing

Keywords: sociolinguistics, linguistic variation, linguistic landscape, spatial humanities, Beirut, Lebanon, Arabic language, geolinguistics, mobile data collection, polyglossia, crowdsourcing

\section{AUTHOR}

\section{DAVID JOSEPH WRISLEY}

New York University Abu Dhabi 